\title{
Multidimensional Contribution of Matrix Metalloproteinases to Atherosclerotic Plaque Vulnerability: Multiple Mechanisms of Inhibition to Promote Stability
}

\author{
Jean Marie Ruddya, ${ }^{a}$ John S. Ikonomidis ${ }^{b, c}$ Jeffrey A. Jones ${ }^{b, c}$ \\ Divisions of a Vascular Surgery, ${ }^{b}$ Cardiothoracic Surgery and ${ }^{\mathrm{c} C}$ Cardiothoracic Research, Department of Surgery, \\ Medical University of South Carolina, Charleston, S.C., USA
}

\section{Key Words}

Atherosclerosis · Plaque rupture - Matrix metalloproteinases . Angiogenesis

\begin{abstract}
The prevalence of atherosclerotic disease continues to increase, and despite significant reductions in major cardiovascular events with current medical interventions, an additional therapeutic window exists. Atherosclerotic plaque growth is a complex integration of cholesterol penetration, inflammatory cell infiltration, vascular smooth muscle cell (VSMC) migration, and neovascular invasion. A family of matrix-degrading proteases, the matrix metalloproteinases (MMPs), contributes to all phases of vascular remodeling. The contribution of specific MMPs to endothelial cell integrity and VSMC migration in atherosclerotic lesion initiation and progression has been confirmed by the increased expression of these proteases in plasma and plaque specimens. Endogenous blockade of MMPs by the tissue inhibitors of metalloproteinases (TIMPs) may attenuate proteolysis in some regions, but the progression of matrix degeneration suggests that MMPs predominate in atherosclerotic plaque, precipitating vulnerability. Plaque neovas-
\end{abstract}

\begin{tabular}{ll}
\hline KARGER & ( 2016 The Author(s) \\
& Published by S. Karger AG, Basel \\
& $1018-1172 / 16 / 0532-0001 \$ 39.50 / 0$ \\
E-Mail karger@karger.com & This article is licensed under the Creative Commons Attribution- \\
www.karger.com/jvr & NonCommercial-NoDerivatives 4.0 International License (CC BY- \\
& NC-ND) (http://www.karger.com/Services/OpenAccessLicense). \\
& Usage and distribution for commercial purposes as well as any dis- \\
tribution of modified material requires written permission.
\end{tabular}

cularization also contributes to instability and, coupling the known role of MMPs in angiogenesis to that of atherosclerotic plaque growth, interest in targeting MMPs to facilitate plaque stabilization continues to accumulate. This article aims to review the contributions of MMPs and TIMPs to atherosclerotic plaque expansion, neovascularization, and rupture vulnerability with an interest in promoting targeted therapies to improve plaque stabilization and decrease the risk of major cardiovascular events.

(c) 2016 The Author(s)

Published by S. Karger AG, Basel

\section{Introduction}

Atherosclerotic plaque deposition occurs in all major vascular beds and is a primary source of morbidity in the USA [1]. While chronic stenosis is often well tolerated due to compensation by collateral vessels, life-threatening consequences may result from plaque rupture with thrombus formation, vessel occlusion, or embolization. Depending on the location, this pathological phenomenon is manifested clinically as a myocardial infarction, limb ischemia, or acute stroke [2]. Medical management of atherosclerosis with antiplatelet agents and statins may

Dr. Jean Marie Ruddy

Division of Vascular Surgery, Department of Surgery

Medical University of South Carolina, 114 Doughty Street, MSC 295

Charleston, SC 29425 (USA)

E-Mail ruddy@musc.edu 
decrease the incidence and severity of events, but additional therapies directed at modification of plaque biology may attenuate growth and promote stability. Recent research has improved the understanding of progression from fatty streaks to mature atheroma with particular attention to inflammatory cell infiltration, vascular smooth muscle cell (VSMC) migration, extracellular matrix (ECM) remodeling, and plaque neovascularization $[3,4]$. All of these processes rely on the production and activation of a subset of enzymes from the family of matrix metalloproteinases (MMPs) [5]. These peptidases have been well studied in various aspects of vascular remodeling [6], but the contribution of MMPs to atherosclerotic plaque neovascularization and rupture vulnerability, with potential targeted therapies to achieve MMP inhibition to promote plaque stabilization, will be the focus of this review.

\section{Atherosclerosis}

A detailed discussion of atherosclerotic plaque deposition is beyond the scope of this article, but key components of the pathophysiology will be introduced to identify pertinent cells, cytokines, growth factors, and enzymes. Endothelial cells (ECs) may become dysfunctional due to pathologic forces such as hypertension, hyperlipidemia, or smoking, and the presence of oxidized low-density lipoprotein (ox-LDL) in the subintimal space can promote the release of chemokines such as monocyte chemoattractant protein-1 [7]. Expression of cell surface adhesion molecules are also upregulated during the initiating phases of fatty streak formation [7]. Adherence and transmigration of monocytes and $\mathrm{T}$ lymphocytes into the intima leads to the release of additional cytokines and growth factors that can stimulate VSMC outgrowth from the media [8]. The VSMC phenotypic switch necessary for migration also supports proliferation and synthetic function [9]. Intraplaque cellular expansion of VSMCs and macrophages progresses to apoptotic degeneration and the formation of a necrotic core covered by a thin fibrous cap of newly synthesized matrix components, a mature atheroma [10]. These latter migration and remodeling processes require matrix degeneration that is mediated by VSMCand macrophage-derived MMP activation and secretion [11]. In early plaque deposition, outward remodeling of the vessel can preserve the lumen area, but this adaptation is frequently overwhelmed by progressive disease and localized vascular stenosis. The stability of these plaques has been attributed to thick fibrous caps [4], while vulnerable plaques are characterized histologically to include a thin cap, with a high macrophage:VSMC ratio, and a large necrotic lipid core [12]. Increased mechanical strain is endured at the shoulder regions of the plaque, a region also noted to have high concentrations of synthetically active macrophages, and contributes to the risk of plaque rupture [13]. Subsequent exposure of thrombogenic substrates and rapid local thrombus formation can then precipitate the clinical consequences of myocardial infarction, acute limb ischemia, or stroke [14]. Understanding the spatial and temporal activity of MMPs in plaque progression and vulnerability may allow targeted therapies to attenuate this unstable vascular remodeling (fig. 1).

\section{Matrix Metalloproteinases}

Regulated activity of the greater than 24 members of the MMP family of zinc-containing proteases allows deconstruction and reorganization of the vascular ECM as well as controlled release of several ECM-embedded cytokines and growth factors. MMPs are categorized into six groups based on substrate specificity, including collagenases (MMP-1, 8, 13, 18), gelatinases (MMP-2, 9), stromelysins (MMP-3, 10, 11), matrilysins (MMP-7, 26), membrane-type (MT1-, 2-, 3-, 4-, 5-, 6-MMP, also known as MMP-14, 15, 16, 17, 24, 25), and others (MMP-12, 19, $21,23,28)$ [15]. Carefully orchestrated control of MMP activity is vital to healthy vessel maintenance and investigation into the consequences of proteolytic imbalance can provide significant insight into the progression of aberrant vascular remodeling [16]. Synthesis may be controlled at the transcriptional, posttranscriptional, and posttranslational levels. Once translated, MMPs are released into the interstitium in a proform that allows zymogen activation to serve as a key mechanism of proteolytic activity management [17]. In addition, the MTMMPs are bound to the cell membrane and thereby limited to pericellular activity and regulated membrane trafficking. An additional point of regulation relies on interactions with the endogenous tissue inhibitors of metalloproteinases (TIMP-1, 2, 3, 4) [18]. Members from each MMP subfamily are represented in atherosclerotic remodeling, providing several potential targets for therapeutic engineering but also displaying the complexity of this pathophysiologic process and suggesting that interruption of a single participant may be inadequate (table 1) [19]. 
Fig. 1. Illustration of the regional distribution of MMPs in atherosclerotic plaque.

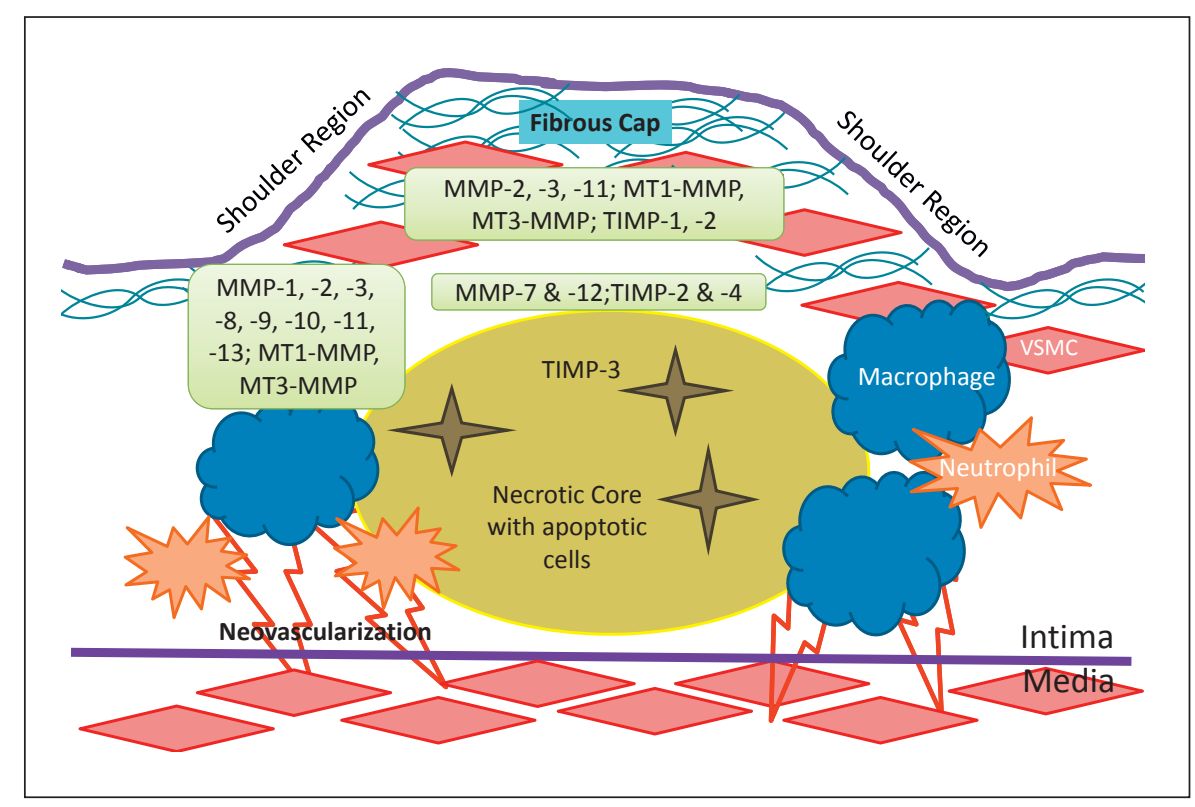

\section{Collagenases}

Fibrillar type I, II, and III collagens, major components of the atheroma fibrous cap, can be cleaved by the collagenases, and overexpression by macrophages, VSMCs, and ECs has been documented in mature atherosclerotic plaques $[20,21]$. More than the inherent cells, it has been postulated that the inflammatory infiltrate plays a primary role in MMP production to breakdown local ECM and alter cap morphology [22]. The localization of MMP-1 to areas of high circumferential stress and of MMP-1, 8, and 13 to the frequently ruptured plaque shoulders supports the critical role of collagenases in fibrous cap thinning and vulnerability [23-25]. Largely outweighing the increased TIMP-1 identified in acute carotid plaque specimens as well as late atheromatous restenotic lesions, amplified MMP-1 expression has demonstrated a critical contribution of this enzyme, and collagen processing in general, to plaque remodeling $[26,27]$. In fact, in a study utilizing extensive histologic and molecular examination of over 50 carotid endarterectomy specimens, only MMP-1 transcript levels were associated with a thin fibrous cap, a potential sign of plaque instability [28]. A specific collagen cleavage-site antibody has further confirmed the activity of macrophage-derived interstitial collagenases MMP-1 and 13, as well as the neutrophil collagenase MMP-8, in inflamed atheromatous plaques $[25,29]$. Intraplaque rupture is a commonly encountered histopathologic abnormality with significant clinical manifestations, particularly in the carotid arterial system, and macrophages at the perimeter of the lipid core were shown to have increased MMP-1 expression that was linearly related to the size of the intraplaque hemorrhage, suggesting that characteristics of plaque instability are augmented by MMP-1 overactivity [23]. Exploring this hypothesis in ApoE knockout mice with macrophage-specific overexpression of MMP-1, however, demonstrated smaller and less mature atheromas and posed the question of how the collagenases contribute to ECM remodeling, such as activity differentiation during plaque initiation, growth, late expansion, or instability [30]. Nevertheless, inhibition of MMP-1 activity should be explored as a means of promoting plaque stability in humans.

MMP-13 has mostly been identified in conjunction with MMP-1, but also offers a significant collagenolytic impact. When concurrently knocked out with ApoE, mice had no change in plaque size but a significant increase in volume and organization of type I collagen fibers, proposing a destabilizing role for MMP-13 [31]. The contribution of neutrophils to atherogenesis continues to be defined and is currently characterized as an early atherogenic inflammatory mediator to assist in monocyte recruitment and contribute to the production of MMP-8 $[32,33]$. Alternatively, MMP-8 has been localized to neutrophils in regions of neovascularization and intraplaque hemorrhage within advanced carotid plaques that demonstrate additional evidence of vulnerability (large lipid 
Table 1. Summary of MMP and TIMP contributions to plaque vulnerability and angiogenesis as well as current data on selective MMP inhibitors

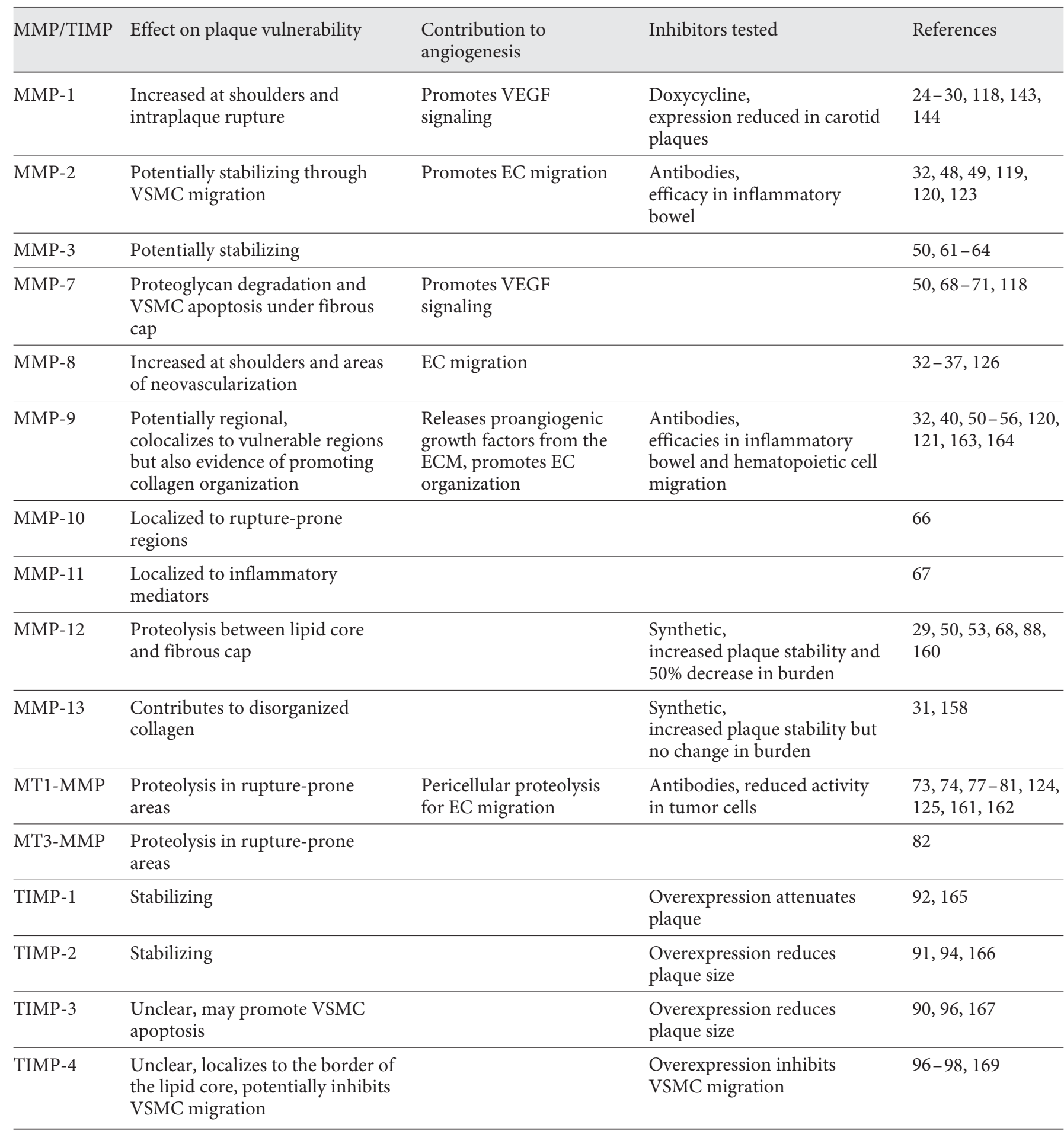


core and high macrophage count), suggesting a contribution of extravasated neutrophils and/or MMP-8 to the rupture risk in these areas [34]. Macrophages are an additional source of MMP-8 in carotid lesions, however, with association of this protease to symptomatic lesions and histologic signs of plaque vulnerability $[35,36]$. Moreover, ApoE knockout mice with a concurrent lack of MMP-8 had smaller aortic lesions with fewer macrophages and higher collagen content, supporting a role for MMP-8 in plaque vulnerability [37].

\section{Gelatinases}

Denatured or degraded products of collagen, referred to collectively as gelatin, and type IV collagen are frequent substrates for MMP-2 and MMP-9, along with elastin, aggrecan, fibronectin, laminin, proteoglycans, and several nonstructural components of the ECM [15]. Gelatinases can provide positive feedback mechanisms to local matrix remodeling by activating pro-MMP-1, pro-MMP-2, proMMP-9, and pro-MMP-13 as well as by modulating the activation of sequestered inflammatory cytokines such as TGF- $\beta 1$, IL- $1 \beta$, and TNF- $\alpha[5,38-40]$. Similar to collagenases, gelatinase activity may be clustered at the shoulder regions of mature atheromas $[20,41]$, but alternative regional cellular contributions are pertinent to early fatty streak progression [14]. VSMCs constitutively express the inactive pro-MMP-2, but inflammatory stimulation will promote phenotypic modulation to support the secretion of all components necessary for zymographically active MMP-2 and MMP-9, enzymes vital to the ECM degradation necessary for VSMC proliferation and migration [42]. Soluble cytokines such as C-reactive protein (CRP) as well as T-lymphocyte-bound CD40L have also demonstrated a targeted increase in MMP-2 expression in VSMCs $[43,44]$. MMP-9 is highly expressed by macrophages [45], and production can be further amplified by exposure to ox-LDL in early atheromas [46]. Neither classical nor alternative macrophage activation effectively enhances MMP-2 production, however, suggesting that VSMCs may be the primary source of MMP-2 in an atheroma [47].

Specifically within atherosclerotic plaques, VSMC migration is imperative for fibrous cap formation, and there are contradictory accounts of the contribution of gelatinases to cap stability. Migration of VSMCs is severely compromised by MMP- 2 deficiency $[48,49]$, and the increased enzymatic activity of MMP-2 identified in fibrous carotid plaques containing a larger proportion of VSMCs suggests an association with stability in this lesion [32].
When MMP-2 was concomitantly knocked out in ApoEdeficient mice, smaller plaques with fewer VSMCs were noted in the murine aorta, implying that MMP-2 is necessary for plaque growth but could also support stability through VSMC migration [49]. Some evidence suggests a role for MMP-9 in modifying plaque growth and promoting collagen organization by VSMCs to potentially enhance plaque stability [50, 51], but MMP-9 colocalization with macrophages and MMP-8 in unstable carotid plaques supports a destabilizing effect in this highly inflammatory, and frequently clinically symptomatic, atheromatous plaque phenotype $[32,52]$. Reductions in aortic plaque burden, macrophage infiltration, and collagen content were observed in ApoE/MMP-9 double knockout mice [53]; however, a separate study with mice of a similar genetic background resulted in more progressive plaque deposition with reduced VSMC density and suspected plaque instability in the brachiocephalic artery [50], demonstrating a potential regional component to MMP-9 contributions to atheroma growth. Additional variation among studies may be attributed to a temporal contribution of MMP-9 to plaque morphology. For instance, in an interesting study utilizing bone marrow transplantation among ApoE/MMP-9 single and double knockout mice, resident arterial cells (VSMCs and ECs) were identified as primary producers of MMP-9 in the early stages of murine brachiocephalic artery atherosclerotic plaque deposition versus late production by infiltrating macrophages [54]. Moreover, late overexpression of MMP-9 in ApoE knockout mice specifically supported intraplaque hemorrhage [55]. In the setting of plaque rupture, the impact of MMP-9 is further perplexing since it can minimize platelet aggregation and degrade fibrin, potentially protecting against thrombus formation, and retroviral overexpression of MMP-9 in ApoE knockout mice failed to show a significant increase in disruption [56-58]. Targeted inhibition of gelatinases, therefore, may be beneficial but individually insufficient to prevent signs of plaque destabilization.

\section{Stromelysins}

Stromelysins act upon a broad range of proteins, but primary substrates for MMP-3, 10, and 11 include nonfibrillar collagens, elastin, fibronectin, proteoglycans, and several nonstructural ECM proteins such as E-cadherin, L-selectin, IL-1 $\beta$, TNF- $\alpha$, and pro-MMP-1, 7, 8, and 9 [15]. MMP-11 demonstrates unique characteristics including secretion in an active form and primary substrate 
specificity for serine protease inhibitors (serpins) [59]. MMP-3 is not produced by healthy vessels, but was one of the first MMPs identified in atherosclerotic plaques, and its expression has been localized to macrophages as well as lymphocytes and activated VSMCs $[42,45,60,61]$. MMP-3 expression can be induced by IL- $1 \beta$ and plateletderived growth factor (PDGF) [62]. Release of ECMbound inflammatory mediators along with the activation of other MMPs suggests a positive feedback mechanism with MMP-3 promoting plaque remodeling. Interestingly, studies of MMP-3/ApoE double knockout mice have shown greater plaque growth with increased macrophage and decreased VSMC composition, signifying impaired VSMC migration and an unstable phenotype in the absence of MMP-3 [50, 63]. The subsequently demonstrated reliance of VSMC migration on MMP-3 activation of MMP-9 likely contributes to this instability and emphasizes the apparent stabilizing effects of MMP-3 [64]. Additional clinical evidence supporting a protective role for MMP-3 includes the impact of the 6A, less transcriptionally active, MMP-3 promoter polymorphism that results in decreased MMP- 3 in these patients and rapid progression of atherosclerotic disease $[65,66]$.

While the specific contribution of MMP-10 to atheroma pathophysiology has not been studied as extensively as MMP-3 due to its association with inflammatory markers such as CRP, serum MMP-10 levels have been gathered for prognostic implications and will be discussed separately [67]. In mature carotid plaques, however, elevated MMP-10 production was quantified in regions heavily populated with macrophages [68]. Likewise, tracking the immune mediator $\mathrm{CD} 40 \mathrm{~L}$ in atherosclerotic plaque cellular constituents allowed for the identification of augmented expression of MMP-11 in mature atherosclerotic plaques while no MMP-11 was visualized in healthy arteries or in fatty streaks [69]. This spatiotemporal expression of MMP-10 and 11 suggests a role for these stromelysins to influence plaque progression with ongoing inflammatory stimulation.

\section{Matrilysin}

MMP-7 has substrate specificity for type IV collagen, elastin, laminin, and proteoglycan as well as several nonstructural ECM components such as $\mathrm{N}$-cadherin, plasminogen, pro-MMP-2, 7, 8, and TNF- $\alpha$ [15]. Of particular note is the high affinity binding domain for versican, a plentiful component of atherosclerotic plaques [70]. Localized production of MMP-7 by fully activated macro- phages has been identified at the interface between the lipid core and fibrous cap, a divergence from the pattern of MMP-1, 3, and 9 secretion at plaque shoulders [70]. Proteolytic activity in this region may weaken apposition of the cap and predispose to plaque rupture, a scenario supported by the elevated MMP-7 plasma levels identified in patients with symptomatic carotid lesions [71]. Transcriptional activation of MMP-7 has been documented in hypoxic macrophages and the relevance of this physiologic adaptation to the regional production in atheromatous plaques remains to be determined [72]; however, a relationship to the initiation of angiogenesis ought to be considered. Attempts to delineate the specific MMP7 contribution to atherosclerotic plaque progression through hypercholesterolemic knockout mice have identified increased VSMC infiltration in the absence of MMP-7 but no alterations in plaque growth or accepted characteristics of stability [50]. The larger contribution of MMP-7 to fibrous cap instability may be related to the initiation of VSMC apoptosis via cleavage of the cell-cell junction protein $\mathrm{N}$-cadherin [73].

\section{Membrane Type}

The MT-MMPs are integral membrane proteins with catalytic domains on the cell surface and contribute to the modification of the pericellular matrix environment [22]. Primary substrates include fibrillar collagens (I, II, and III), aggrecan, fibronectin, proteoglycans, and nonstructural ECM proteins including integrins, pro-MMP-2 and 13 , and pro-TNF- $\alpha$ [15]. MT1-MMP is constitutively expressed by VSMCs in healthy vessels with additional expression in atherosclerotic plaques [74]. The induction of MT1-MMP in ECs following exposure to ox-LDL or TNF- $\alpha$ may indicate a mechanism for early degradation of the intima to facilitate inflammatory cell infiltration [75]. In addition to a role in monocyte penetration through the endothelium [76], MT1-MMP has been shown to promote VSMC migration and proliferation by mechanical degradation of adhesion points to the basement membrane [77]. Overexpression of MT1-MMP has also been documented at rupture-prone areas of atherosclerotic plaques $[74,75$, $78,79]$. Potentially the most important contribution of MT1-MMP in atherosclerotic plaque progression, however, is the concomitant increased activation of pericellular MMP-2 [80]. Mice in which MT1-MMP has been knocked out display a severe dysmorphism and typically die within 3 weeks of birth. As such, these mice are unable to be studied in adulthood, significantly limiting the op- 
portunities to isolate and define the role of this MMP in atherosclerosis [81]. Bone marrow transplantation from MT1-MMP knockout mice into radiated ApoE knockout mice, however, has demonstrated increased collagen content with no change in plaque burden, supporting a primarily collagenolytic role for MT1-MMP $[82,83]$.

\section{Other MMPs}

Within this group of miscellaneous MMPs, the most pertinent contribution to atherosclerotic plaque growth and potential rupture has been documented for MMP-12, also known as macrophage metalloelastase $[15,84]$. In addition to elastin, major substrates include type IV collagen, fibronectin, plasminogen, and pro-MMP-2 and 3 $[15,85]$. The indispensable contribution of this protease to basement membrane degradation has implications for macrophage infiltration in response to inflammatory mediators [86-88]. Interestingly, increased synthesis and secretion of MMP-12 has been localized to mature macrophages at the border zone between the lipid core and fibrous cap, a region where ECM degradation may predispose to rupture [70]. This spatial distribution supports the elevated MMP-12 expression documented in ruptured, symptomatic carotid plaque specimens, and patients with elevated MMP-12 levels within the extracted plaques had a higher risk of cardiovascular complications perioperatively $[28,89]$. Moreover, genome-wide analysis identified an overexpression of MMP-12 in patients with large artery atherosclerosis as their stroke etiology [90]. Temporal analysis of MMP-12 production in rabbit atherosclerotic plaque has indicated a lack of MMP-12 in healthy vessels with marked upregulation in progressive lesions, again supporting the association with mature macrophages and rupture morphology [91]. ApoE/ MMP-12 double knockout mice had no alteration of plaque accumulation in the aorta, but in the brachiocephalic artery there was increased VSMC infiltration, decreased macrophage penetration, and decreased elastin degradation, suggesting properties of a more stable plaque phenotype in the knockout mouse and supporting a destructive role for MMP-12 in plaque progression $[50,53]$.

\section{Tissue Inhibitors of Metalloproteinases}

Tissue inhibitors of metalloproteinases (TIMPs) are expressed during development and tissue remodeling and play a major role in regulating MMP activity under healthy as well as pathologic conditions [92]. Considering the four TIMPs identified in humans, all MMPs may be inhibited but individual affinity does vary, such as a lack of activity between TIMP-1 and MT-MMPs [93]. TIMP1 and TIMP-2 are constitutively expressed by VSMCs, but expression cannot be augmented by inflammatory cytokines that contribute to enhanced MMP production by VSMCs in atherosclerotic disease, providing one avenue by which the balance may favor proteolytic activity in these regions [94]. Interestingly, TIMP-1 production by VSMCs has been enhanced by PDGF, a frequent contributor to matrix remodeling [95]. Shared utilization of binding sites for the AP-1 transcription factor may indicate how TIMP-1 may be coexpressed with collagenases such as MMP-1 and MMP-13 to modulate matrix degeneration [96]. Experimental manipulation of TIMP-1 production has suggested that this protein plays a significant role in limiting plaque progression, however, since larger lesions grew in TIMP-1/ApoE knockout mice [97]. Localization of TIMP-1 to macrophage-rich regions of plaque led to further experimentation regarding local expression and the observation that ox-LDL decreased TIMP- 1 expression in macrophages, while the production of several MMPs was not affected [98]. Oxidation of LDL molecules trapped in the intima has been described as an early trigger for EC expression of adhesion molecules and chemokines that initiate fatty streak deposition [8]; therefore, the decreased TIMP-1 production by these early infiltrating macrophages may provide an early mechanism for MMP/TIMP imbalance and ECM degradation.

High levels of TIMP-2 have been noted in macrophages overlying the lipid core as well as along the intima-media border, potentially stabilizing locations confirmed by the decreased activity observed by in situ gelatin zymography in these regions $[95,99]$. TIMP-3 has minimal secretion from healthy VSMCs, is tightly sequestered in the ECM, and has demonstrated augmented expression by VSMCs in response to PDGF and TGF- $\beta$ but no change for inflammatory cytokines associated with atherosclerosis, potentiating a state of dysregulated MMP activity during atherogenesis $[94,100]$. Interestingly, TIMP-3 colocalized with apoptotic markers in the necrotic lipid core of mature atherosclerotic plaques, implying that the described role of nonphysiologic TIMP-3 overexpression in VSMC apoptosis in vitro may contribute to plaque physiology in vivo $[93,101]$. TIMP-3 expression by activated macrophages was decreased following exposure to ox-LDL or inflammatory cytokines, known stimulators of MMP production in these cells [79]. TIMP-4 has a restricted expression profile limited to cardiovascular tissues [102], and production 
of TIMP- 4 has been reported in the media and adventitia of healthy vessels, but localization to macrophages bordering the necrotic lipid core has also associated this protein with active inflammatory processes $[101,103]$.

\section{Regulation by microRNA}

Short, single-stranded segments of RNA, known as microRNA (miRNA), are recognized regulators of gene expression implicated in numerous physiologic and pathophysiologic processes, including the initiation and progression of vascular diseases [104]. These molecules can downregulate target genes through mRNA degradation or by repressing translation, and each miRNA can influence several genes, demonstrating how these interactions may influence entire signaling pathways [105]. Particular to atherosclerotic disease, multiple miRNAs have amplified expression in plaque specimens from peripheral arteries, including miR-21, miR-34, miR-146a, miR-146b-5p, and miR-210, with corresponding attenuation of expected target gene levels. The inflammatory response known to contribute to atheroma growth has likewise been associated with particular miRNAs [106, 107], but those regulating MMP and TIMP production will be selectively further discussed.

The association of miR-21 with adverse cardiovascular events due to the promotion of neointimal lesions was strengthened with the identification of RECK as a target gene [108]. Overexpression of miR-21 in macrophages induced increased secretion of pro-MMP-9 as well as active MMP-9 by inhibiting RECK expression [108]. Additional epigenetic manipulation of MMP-9 and MMP-2 production has been attributed to miR-29b targeting of DNA methylation genes that are upstream of gelatinase transcription [109], and a single-site polymorphism has been demonstrated to effect a significant amplification of MMP-9 production due to the loss of activity of miR-491, ultimately leading to an increased risk of ischemic stroke [110]. This relationship between miRNAs and atherosclerotic plaque stability has been greatly expanded with the identification of a group of miRNAs that influence plaque homeostasis. Through comparative analysis of miRNA profiles in symptomatic versus asymptomatic carotid plaques, miR-100, miR-127, miR-133a, miR-133b, and miR-145 were found to be jointly upregulated in symptomatic - and presumed unstable - plaques [111]. Bioinformatic analysis identified MMP-9 as a potential target of $\mathrm{miR}-133 \mathrm{a}$ and $\mathrm{miR}-133 \mathrm{~b}$, and this association was subsequently proven by decreased MMP-9 production in the presence of miR-133a mimic, and additional reports implicate this group of miRNAs in regulating MMP-13 as well, thereby providing a means of impacting plaque remodeling and potential stability through two powerful proteases [111]. Stabilizing effects have also been demonstrated with miRNA-24 through the downregulation of MT1-MMP and decreased invasion of macrophages [112]. Factors regulating miRNA production continue to be explored and utilizing this avenue to modulate MMP production may be a viable asset in the future.

\section{Biomarkers}

Having recognized several MMPs and TIMPs as key players in atherosclerotic plaque rupture with consequent clinical cardiovascular manifestations such as myocardial infarction or stroke, interest in measuring the plasma levels of these proteins to help identify high-risk patients has continued to rise. Early studies following patients with moderate carotid atherosclerotic disease found elevated MMP-9 levels to be associated with an increased incidence of stroke or cardiovascular death over a 10-year follow-up timeframe [113]. More specifically, elevated MMP-9 correlated to ultrasonographic as well as postsurgical histologic signs of plaque instability, including increased intima-media thickness (IMT), a thinner fibrous cap, and the presence of intraplaque hemorrhage [114, 115]. Examining a broader scope of the proteolytic environment in patients presenting for carotid endarterectomy, those with unstable plaques had higher plasma levels of MMP-1, 2, 3, and 9 coinciding with lower levels of TIMP-1 and 2 when compared to those with stable plaques as well as to healthy age-matched volunteers $[116$, 117]. Continuing to monitor these proteins along with the surveillance carotid artery duplex ultrasound imaging in postendarterectomy patients may prove efficacious given that those with late symptomatic recurrence of carotid stenosis have shown increased MMP-2 and 9 and decreased TIMP-1 and 2 plasma levels compared not only to healthy volunteers, but also to those with asymptomatic restenosis, suggesting that these proteins may mark patients with more aggressive, unstable disease [118]. Of the participants in the Atherosclerosis Risk in Communities Carotid MRI Study, those with high IMT also demonstrated elevated MMP-1, 3, and 7 levels, while the normalized wall index, an MRI-derived value comparing the wall area to total vessel area, positively correlated with MMP-3, 7, and TIMP-1 [119]. Because this study associated serum levels with high-resolution cross-sectional 
imaging, it was also able to make a positive association between TIMP-1 and fibrous cap thickness, likely indicating plaque stability [119].

Alternatively, the ultrasonographic evidence of hypoechogenic plaque has been associated with elevated MMP-8 serum levels in asymptomatic patients undergoing carotid endarterectomy, and those with high levels of MMP-8 within the endarterectomized plaque had a greater than 4-fold increased risk of a cardiovascular event in the ensuing 3 years $[120,121]$. Likewise, patients with plaques possessing elevated MMP-12 have a greater than 3 -fold risk of stroke over the same timeframe [89]. Those with preoperative symptomatic carotid lesions have demonstrated elevated plasma levels of MMP-7 and associated increased all-cause mortality during an 8-year follow-up period, with this correlation being stronger than that between either age or increased CRP and mortality in this population [71]. Tracking the inflammatory biomarker CRP has repeatedly proven to be prognostic for stroke, however, and colocalization of MMP-10 with CRP in rupture-prone regions of carotid atherosclerotic plaques has led to the investigation of MMP-10 as a clinically relevant biomarker, particularly in patients with elevated CRP [67, 68]. Patients lacking clinical evidence of cardiovascular disease but maintaining elevated CRP values have demonstrated concurrent elevation of MMP-10 as well as increased carotid IMT, suggesting that this enzyme may serve as an effective screening tool for subclinical atherosclerotic disease $[68,122]$. When studied in smokers with cardiovascular risk factors but no clinical symptoms, MMP-10 was significantly elevated while inflammatory markers, other MMPs, and TIMP-1 remained stable [123]. Integration of biomarker and biochemical data may facilitate the identification of which MMP isotypes would be most efficacious to target pharmaceutically.

\section{Plaque Neovascularization and Vulnerability}

Advanced atherosclerotic lesions may become infiltrated by vessels of the vasa vasorum in response to hypoxia and inflammatory mediators [124]. This centripetal angiogenesis is frequently localized to the plaque shoulders, suspected to begin early in lesion progression beyond fatty streaks, and regarded as the likely source of intraplaque hemorrhage, providing another mechanism for plaque instability [3, 125-127]. In fact, a greater density and tortuosity of infiltrating vessels has been associated with symptomatic carotid plaques [128]. Furthermore, carotid plaque neovascular density and the pres- ence of intraplaque hemorrhages have been identified as independent predictors of cardiovascular events [129]. Therefore, promoting plaque stability may require quenching matrix proteolysis along with deterring EC invasion. MMPs are the point of intersection between these vascular remodeling processes.

Potent angiogenic growth factors such as FGFs, VEGF, and TGF- $\beta$ may be released from ECM sequestration through the local activity of MMPs induced during plaque progression, and these proteases are also instrumental in degrading pericyte and EC attachments [17]. For instance, MMP-1 and 7 can promote signaling through the VEGF receptor to upregulate EC proliferation, migration, and tube formation [130, 131]. The gelatinases and MT1MMP have been heavily studied in developmental and pathologic angiogenesis and are of particular interest given that FGF as well as VEGF can stimulate ECs to secrete vesicles containing MMP-2, MMP-9, and MT1-MMP, thereby increasing and potentially initiating local proteolysis [132, 133]. MMP-9 can release ECM-bound growth factors, expose proangiogenic collagen-binding sites, and contribute to basement membrane degradation, while selective inhibition of MMP-9 in vitro results in decreased EC organization [40, 134]. MMP-2 is constitutively expressed by ECs and plays an essential role in proliferation, differentiation, and migration, but variations in the MT1MMP activation complex may also cause MMP-2 to promote apoptosis, an additional mechanism for angiogenesis regulation that may be exploited during plaque progression [135].In its location on the EC surface, MT1-MMP plays a significant role in pericellular proteolysis for migration and invasion; in fact MT1-MMP collagenase activity is required for EC tube construction in $3 \mathrm{D}$ collagen matrices as a precursor for vessel formation [136, 137].

Animal models exploring the functional overlap of MMPs involved in atherogenesis and angiogenesis have provided interesting results. Utilizing ApoE/MMP-8 double knockout mice to establish a role for this enzyme specifically in plaque neovascularization, investigators discovered that the atherosclerotic burden was decreased, aortic specimens had less EC sprouting, and cultured ECs from double knockout mice had impaired proliferation and migration [138]. Viral transfection to inhibit MMP-8 translation in human ECs in vitro confirmed decreased migration and identified downregulation of the angiotensin II signaling pathway as a key contributor to the altered gene expression and EC phenotype in the absence of MMP-8 [138]. Alternatively, in a hypercholesteremic rabbit model of aortic atherosclerotic plaque deposition, in situ levels of MMP-1, 2, 3, 9, MT1-MMP, and VEGF 
were quantitated at 2-week intervals and the plaques underwent histologic examination to document IMT, the vulnerability index (VI), and microvessel density (MVD) [139]. With progressive plaque growth, the expression of MMP-1, 2, 3, 9, and VEGF increased along with the VI, a value describing the macrophage and lipid components divided by the VSMC and collagen components [139]. Microvessels began to incorporate into plaques at 8 weeks and the MVD increased until 12 weeks at the conclusion of the study [139]. Surprisingly, MT1-MMP expression decreased throughout the study and was negatively correlated with VI as well as MVD [139], suggesting that EC liberation from the basement membrane may be achieved through different MMPs in diseased adventitia versus healthy tissues. Mediation of neovascularization through the VEGF signaling pathway appears to be preserved in atheromas, however, providing another avenue for potential therapeutic intervention. Despite significant progress, the definition of the key growth factors, proteases, and timeframe for neovascularization will be instrumental in further attempts to stabilize atherosclerotic plaques through the inhibition of angiogenesis.

\section{Targets to Promote Plaque Stabilization}

Medical management of atherosclerotic disease has significantly improved over the past 2 decades, reducing the incidence of major cardiovascular events in Westernized countries and supporting the paradigm that pharmaceutical plaque stabilization is a clinically relevant treatment goal [1]. Given the mounting pathophysiologic evidence that MMPs play a major role in plaque vulnerability, significant efficacy may be expected by targeting these remodeling proteases. Mouse models describing significant plaque alterations with selective MMP knockout or TIMP overexpression certainly support this line of pharmaceutical development, but the congenital abnormalities identified in these strains also forewarn of complex side effect profiles [140]. Further proof of concept has been derived from clinical reports of decreased rates of major cardiovascular events together with in vitro studies reporting modulation of MMP activity by HMG CoA reductase inhibitors (statins) as well as peroxisome proliferator activator receptor (PPAR- $\alpha$ and $\gamma$ ) agonists, two medication classes frequently administered to patients with peripheral arterial disease [141-147]. Unfortunately, plaque rupture events do still occur, however, and directly targeting MMPs may provide additional preventive measures to decrease the associated morbidity and mortality.
Interest in engineering molecules to target MMPs has progressed since their role in tumor metastasis was identified and has not only endured despite several failures, but also expanded to consider therapies for arthritis, periodontal disease, and several cardiovascular diseases. Basic inhibition involves chelation of the active site zinc ion with the addition of alternative affinity sites to provide specificity and attempt to minimize side effects, most notably the musculoskeletal syndrome [148, 149]. Several synthetic nonselective MMP inhibitors have been constructed but studies of systemic as well as local administration have failed to demonstrate a meaningful impact on vascular remodeling, though it ought to be noted that very few of these investigations focused on peripheral arteries [150-153]. Doxycycline, a downregulator of general MMP activity, is currently approved in a low-dose form to treat periodontal disease, but its efficacy in attenuating atherosclerotic disease has been questionable [154]. This pharmaceutical has failed to minimize cardiovascular events in a randomized study of patients with stable coronary artery disease, and although carotid endarterectomy specimens have demonstrated good doxycycline penetration and reduced MMP-1 expression in the plaque after oral therapy for 2-8 weeks, no changes in plaque morphology or clinical outcome were noted, suggesting that the inhibition of alternative or additional MMPs may be necessary $[155,156]$.

Targeting a select MMP within an atherosclerotic plaque poses a significant challenge and these complex molecules have not yet reached clinical trials. Advanced biochemical methods have produced selective inhibitors of MMP-1, 2, 3, 8, 9, 12, and 13, but few have been tested in animal models thus far [157-171]. Increased collagen was noted in the plaques of ApoE knockout mice treated with an MMP-13 inhibitor, a marker of plaque stability, but no change in plaque burden could be appreciated [170]. The most promising results have been observed when these proatherogenic mice were treated with a selective MMP- 12 inhibitor, where a $50 \%$ decrease in plaque burden, increased VSMC:macrophage ratio, smaller necrotic cores, and increased fibrous cap thickness were documented, supporting MMP-12 as a pertinent target for therapeutic strategies [172]. An alternative approach has involved the generation of humanized monoclonal antibodies and successful inhibition of MT1-MMP activity has been reported in tumor cells, with a concurrent decrease in the activation of pro-MMP-2 [173, 174]. An animal model of inflammatory bowel disease has been utilized to demonstrate the efficacy of an antibody for MMP-2 and 9, but applications to vascular remodeling 
have not been pursued [175]. An MMP-9-specific antibody has also been developed and proved to effectively inhibit hematopoietic cell mobilization in nonhuman primates, but further investigation into human trials has not occurred [176]. These encouraging results in animal models support the continued development of smallmolecule MMP inhibitors to maximize bioavailability and minimize side effects so that efficacy in atherosclerotic disease may be assessed.

Interestingly, despite the significant morbidity of the musculoskeletal syndrome with general MMP inhibitors, overexpression of TIMPs has not produced this debilitating tendonitis in murine models. TIMP-1 overexpression in ApoE knockout mice has been shown to attenuate plaque progression [177]. TIMP-2 overexpression in ApoE knockout mice also reduced plaque size and increased histologic markers of plaque stability through inhibition of macrophage migration and apoptosis [178]. Targeted overexpression of TIMP-3 in macrophages effectively reduced plaque size and inflammatory infiltrate while promoting plaque stabilization through increased intact collagen, supporting TIMP-3 as a key mediator of proteolytic activity [179]. Adenovirus-mediated overexpression of TIMP-4 in carotid and aortic VSMCs effectively inhibited MMP-2 activation and VSMC migration while inducing apoptosis in these cells [180], but appropriate application of this data to atherosclerotic plaque stability requires further investigation. The safe and effective delivery of these adenoviruses to atherosclerotic plaques poses a significant challenge, but investigation into utilization of genetic variants has been initiated [181]

Another approach to stabilizing existing plaques may be through the inhibition of angiogenesis. For instance, treating ApoE knockout mice with angiostatin, endostatin, or TNP-470, all known angiogenesis inhibitors that prevent EC proliferation and migration, successfully decreased atherosclerotic plaque growth and neovascularization when the drug was administered at late stages of plaque progression $[182,183]$. Initiation of treatment at a younger age and continuation during the administration of a hypercholesterolemic diet, however, did not influence fatty streak and early fibrous lesion development in these mice [183], supporting the contribution of angiogenesis to late plaque growth and instability, and suggesting that an alternative method of targeting vessel growth may be more beneficial. As discussed earlier, several proangiogenic growth factors may be liberated from the local ECM through MMP activity, but these peptides also stimulate MMP expression. FGF-1 can impact on the early stages of angiogenesis by upregulating MMP-1 expres- sion, FGF-2 can induce synthesis of MMP-2, 3, 7, 9, 10, 11 , and 13, PDGF promotes MMP-13 transcription, and VEGF can stimulate the production of MMP-2 [184187], all major contributors to EC migration and atherosclerotic plaque vulnerability, therefore modulation of growth factor binding may decrease MMP secretion and prevent EC migration to combine two potent mechanisms of plaque stabilization. Unfortunately, clinical trials of monoclonal antibodies for some proangiogenic growth factors/receptors, especially those targeting VEGF, have demonstrated a prohibitively high rate of cardiovascular complications [188]. Exploration of this paradox with the ApoE knockout mouse has yielded conflicting results. Adenovirus-mediated overexpression of VEGF had no effect on aortic atherosclerotic plaque deposition or neovascularization [189], but systemic therapy with VEGF inhibitor led to accelerated atherogenesis [190]. Newer oncologic antiangiogenesis agents targeting combinations of the FGF, PDGF, and/or VEGF receptors have not demonstrated similar toxicities but evaluation in the treatment of peripheral arterial disease has not been pursued [191-193]. The long-term therapy required for a chronic disease such as peripheral artery disease may be another limiting factor in the utilization of these pharmaceuticals; therefore, research pursuing the more specific alternative of a selective MMP inhibitor to mitigate plaque neovascularization may be a more productive avenue.

\section{Conclusion}

Despite advances in pharmacologic therapy, atherosclerosis with vulnerable plaque morphology continues to contribute to morbidity and mortality in Westernized countries. Knowledge of the intraplaque pathophysiology resulting in instability continues to accumulate, but viable therapies to quench proteolysis or angiogenesis are increasingly complex due to the recognized necessity for selective, targeted agents so that patient tolerance may be maximized. Focusing on the generation and activity of MMPs in both atherosclerosis and angiogenesis provides a unified pathway toward plaque stability and continued research into the delivery and bioavailability of selective MMP inhibitors is warranted.

\section{Disclosure Statement}

The authors have no relevant disclosures. 


\section{References}

1 Jemal A, Ward E, Hao Y, Thun M: Trends in the leading causes of death in the United States, 1970-2002. JAMA 2005;294:12551259.

2 Gallino A, Aboyans V, Diehm C, et al: Noncoronary atherosclerosis. Eur Heart J 2014;35: 1112-1119.

3 Ho-Tin-Noe B, Michel JB: Initiation of angiogenesis in atherosclerosis: smooth muscle cells as mediators of the angiogenic response to atheroma formation. Trends Cardiovasc Med 2011;21:183-187.

4 Kaperonis EA, Liapis CD, Kakisis JD, Dimitroulis D, Papavassiliou VG: Inflammation and atherosclerosis. Eur J Vasc Endovasc Surg 2006;31:386-393.

5 Back M, Ketelhuth DF, Agewall S: Matrix metalloproteinases in atherothrombosis. Prog Cardiovasc Dis 2010;52:410-428.

6 Hobeika MJ, Thompson RW, Muhs BE, Brooks PC, Gagne PJ: Matrix metalloproteinases in peripheral vascular disease. J Vasc Surg 2007;45:849-857.

7 Erl W, Weber PC, Weber C: Monocytic cell adhesion to endothelial cells stimulated by oxidized low density lipoprotein is mediated by distinct endothelial ligands. Atherosclerosis 1998;136:297-303.

8 Weber C, Noels H: Atherosclerosis: current pathogenesis and therapeutic options. Nat Med 2011;17:1410-1422.

9 Campbell JH, Campbell GR: The role of smooth muscle cells in atherosclerosis. Curr Opin Lipidol 1994;5:323-330.

10 Rafieian-Kopaei M, Setorki M, Doudi M, Baradaran A, Nasri H: Atherosclerosis: process, indicators, risk factors and new hopes. Int J Prev Med 2014;5:927-946.

11 Lijnen HR: Metalloproteinases in development and progression of vascular disease. Pathophysiol Haemost Thromb 2003;33:275281.

12 Virmani R, Burke AP, Farb A, Kolodgie FD: Pathology of the vulnerable plaque. J Am Coll Cardiol 2006;47(8 suppl):C13-C18.

13 Newby AC, George SJ, Ismail Y, Johnson JL, Sala-Newby GB, Thomas AC: Vulnerable atherosclerotic plaque metalloproteinases and foam cell phenotypes. Thromb Haemost 2009;101:1006-1011.

14 Orford JL, Selwyn AP, Ganz P, Popma JJ, Rogers C: The comparative pathobiology of atherosclerosis and restenosis. Am J Cardiol 2000;86(4B):6H-11H.

15 Benjamin MM, Khalil RA: Matrix metalloproteinase inhibitors as investigative tools in the pathogenesis and management of vascular disease. EXS 2012;103:209-279.

16 Dollery CM, McEwan JR, Henney AM: Matrix metalloproteinases and cardiovascular disease. Circ Res 1995;77:863-868.

17 Raffetto JD, Khalil RA: Matrix metalloproteinases and their inhibitors in vascular remodeling and vascular disease. Biochem Pharmacol 2008;75:346-359.
18 Visse R, Nagase H: Matrix metalloproteinases and tissue inhibitors of metalloproteinases: structure, function, and biochemistry. Circ Res 2003;92:827-839.

19 Newby AC: Metalloproteinases and vulnerable atherosclerotic plaques. Trends Cardiovasc Med 2007;17:253-258.

20 Galis ZS, Sukhova GK, Lark MW, Libby P: Increased expression of matrix metalloproteinases and matrix degrading activity in vulnerable regions of human atherosclerotic plaques. J Clin Invest 1994;94:2493-2503.

21 Nagase H, Visse R, Murphy G: Structure and function of matrix metalloproteinases and TIMPs. Cardiovasc Res 2006;69:562-573.

22 Newby AC: Role of metalloproteinases in plaque rupture. Int J Gerontol 2007;1:103111.

23 Nikkari ST, O’Brien KD, Ferguson M, et al: Interstitial collagenase (MMP-1) expression in human carotid atherosclerosis. Circulation 1995;92:1393-1398.

24 Lee RT, Schoen FJ, Loree HM, Lark MW, Libby P: Circumferential stress and matrix metalloproteinase 1 in human coronary atherosclerosis: implications for plaque rupture. Arterioscler Thromb Vasc Biol 1996;16: 1070-1073.

25 Sukhova GK, Schonbeck U, Rabkin E, et al: Evidence for increased collagenolysis by interstitial collagenases- 1 and -3 in vulnerable human atheromatous plaques. Circulation 1999;99:2503-2509.

26 Higashikata T, Yamagishi M, Higashi T, et al: Altered expression balance of matrix metalloproteinases and their inhibitors in human carotid plaque disruption: results of quantitative tissue analysis using real-time RT-PCR method. Atherosclerosis 2006;185:165-172.

27 Nikkari ST, Geary RL, Hatsukami T, et al: Expression of collagen, interstitial collagenase, and tissue inhibitor of metalloproteinases-1 in restenosis after carotid endarterectomy. Am J Pathol 1996;148:777-783.

28 Morgan AR, Rerkasem K, Gallagher PJ, et al: Differences in matrix metalloproteinase-1 and matrix metalloproteinase- 12 transcript levels among carotid atherosclerotic plaques with different histopathological characteristics. Stroke 2004;35:1310-1315.

29 Herman MP, Sukhova GK, Libby P, et al: Expression of neutrophil collagenase (matrix metalloproteinase-8) in human atheroma: a novel collagenolytic pathway suggested by transcriptional profiling. Circulation 2001; 104:1899-1904

30 Lemaitre V, O’Byrne TK, Borczuk AC, Okada Y, Tall AR, D’Armiento J: ApoE knockout mice expressing human matrix metalloproteinase- 1 in macrophages have less advanced atherosclerosis. J Clin Invest 2001;107:12271234
31 Deguchi JO, Aikawa E, Libby P, et al: Matrix metalloproteinase-13/collagenase-3 deletion promotes collagen accumulation and organization in mouse atherosclerotic plaques. Circulation 2005;112:2708-2715.

32 Sluijter JP, Pulskens WP, Schoneveld AH, et al: Matrix metalloproteinase 2 is associated with stable and matrix metalloproteinases 8 and 9 with vulnerable carotid atherosclerotic lesions: a study in human endarterectomy specimen pointing to a role for different extracellular matrix metalloproteinase inducer glycosylation forms. Stroke 2006;37:235-239.

33 Drechsler M, Megens RT, van Zandvoort M, Weber C, Soehnlein O: Hyperlipidemia-triggered neutrophilia promotes early atherosclerosis. Circulation 2010;122:1837-1845

34 Ionita MG, van den Borne P, Catanzariti LM, et al: High neutrophil numbers in human carotid atherosclerotic plaques are associated with characteristics of rupture-prone lesions. Arterioscler Thromb Vasc Biol 2010;30: 1842-1848.

35 Dollery CM, Owen CA, Sukhova GK, Krettek A, Shapiro SD, Libby P: Neutrophil elastase in human atherosclerotic plaques: production by macrophages. Circulation 2003;107:28292836.

36 Molloy KJ, Thompson MM, Jones JL, et al: Unstable carotid plaques exhibit raised matrix metalloproteinase- 8 activity. Circulation 2004;110:337-343.

37 Laxton RC, Hu Y, Duchene J, et al: A role of matrix metalloproteinase- 8 in atherosclerosis. Circ Res 2009;105:921-929.

38 Gearing AJ, Beckett P, Christodoulou M, et al: Processing of tumour necrosis factor-alpha precursor by metalloproteinases. Nature 1994;370:555-557.

39 Schonbeck U, Mach F, Libby P: Generation of biologically active IL- $1 \beta$ by matrix metalloproteinases: a novel caspase-1-independent pathway of IL-1 $\beta$ processing. J Immunol 1998;161:3340-3346.

$40 \mathrm{Yu}$ Q, Stamenkovic I: Cell surface-localized matrix metalloproteinase- 9 proteolytically activates TGF- $\beta$ and promotes tumor invasion and angiogenesis. Genes Dev 2000;14: 163-176.

41 Amorino GP, Hoover RL: Interactions of monocytic cells with human endothelial cells stimulate monocytic metalloproteinase production. Am Journal Pathol 1998;152:199207.

42 Galis ZS, Muszynski M, Sukhova GK, et al: Cytokine-stimulated human vascular smooth muscle cells synthesize a complement of enzymes required for extracellular matrix digestion. Circ Res 1994;75:181-189.

43 Doronzo G, Russo I, Mattiello L, Trovati M, Anfossi G: C-reactive protein increases matrix metalloproteinase-2 expression and activity in cultured human vascular smooth muscle cells. J Lab Clin Med 2005;146:287298 . 
44 Schonbeck U, Mach F, Sukhova GK, et al: Regulation of matrix metalloproteinase expression in human vascular smooth muscle cells by T lymphocytes: a role for CD 40 signaling in plaque rupture? Circ Res 1997;81:448454.

45 Chase AJ, Bond M, Crook MF, Newby AC: Role of nuclear factor- $\kappa \mathrm{B}$ activation in metalloproteinase- $1,-3$, and -9 secretion by human macrophages in vitro and rabbit foam cells produced in vivo. Arterioscler Thromb Vasc Biol 2002;22:765-771.

46 Xu XP, Meisel SR, Ong JM, et al: Oxidized low-density lipoprotein regulates matrix metalloproteinase- 9 and its tissue inhibitor in human monocyte-derived macrophages. Circulation 1999;99:993-998.

47 Huang WC, Sala-Newby GB, Susana A, Johnson JL, Newby AC: Classical macrophage activation up-regulates several matrix metalloproteinases through mitogen activated protein kinases and nuclear factor- $\kappa B$. PLoS One 2012;7:e42507.

48 Hlawaty H, Suffee N, Sutton A, et al: Low molecular weight fucoidan prevents intimal hyperplasia in rat injured thoracic aorta through the modulation of matrix metalloproteinase- 2 expression. Biochem Pharmacol 2011; 81:233-243.

49 Kuzuya M, Nakamura K, Sasaki T, Cheng $\mathrm{XW}$, Itohara S, Iguchi A: Effect of MMP-2 deficiency on atherosclerotic lesion formation in apoE-deficient mice. Arterioscler Thromb Vasc Biol 2006;26:1120-1125.

50 Johnson JL, George SJ, Newby AC, Jackson CL: Divergent effects of matrix metalloproteinases $3,7,9$, and 12 on atherosclerotic plaque stability in mouse brachiocephalic arteries. Proc Natl Acad Sci USA 2005;102: 15575-15580.

51 Johnson C, Galis ZS: Matrix metalloproteinase-2 and - 9 differentially regulate smooth muscle cell migration and cell-mediated collagen organization. Arterioscler Thromb Vasc Biol 2004;24:54-60.

52 Loftus IM, Naylor AR, Goodall S, et al: Increased matrix metalloproteinase- 9 activity in unstable carotid plaques: a potential role in acute plaque disruption. Stroke 2000;31:4047.

53 Luttun A, Lutgens E, Manderveld A, et al: Loss of matrix metalloproteinase- 9 or matrix metalloproteinase- 12 protects apolipoprotein E-deficient mice against atherosclerotic media destruction but differentially affects plaque growth. Circulation 2004;109:14081414.

54 Choi ET, Collins ET, Marine LA, et al: Matrix metalloproteinase- 9 modulation by resident arterial cells is responsible for injury-induced accelerated atherosclerotic plaque development in apolipoprotein E-deficient mice. Arterioscler Thromb Vasc Biol 2005;25:10201025 .
55 de Nooijer R, Verkleij CJ, von der Thusen JH, et al: Lesional overexpression of matrix metalloproteinase- 9 promotes intraplaque hemorrhage in advanced lesions but not at earlier stages of atherogenesis. Arterioscler Thromb Vasc Biol 2006;26:340-346.

56 Fernandez-Patron C, Martinez-Cuesta MA, Salas E, et al: Differential regulation of platelet aggregation by matrix metalloproteinases- 9 and -2. Thromb Haemost 1999;82:17301735 .

57 Lelongt B, Bengatta S, Delauche M, Lund LR, Werb Z, Ronco PM: Matrix metalloproteinase 9 protects mice from anti-glomerular basement membrane nephritis through its fibrinolytic activity. J Exp Med 2001;193:793802.

58 Gough PJ, Gomez IG, Wille PT, Raines EW: Macrophage expression of active MMP-9 induces acute plaque disruption in apoE-deficient mice. J Clin Invest 2006;116:59-69.

59 Pei D, Weiss SJ: Furin-dependent intracellular activation of the human stromelysin-3 zymogen. Nature 1995;375:244-247.

60 Bond M, Chase AJ, Baker AH, Newby AC: Inhibition of transcription factor NF- $\mathrm{KB}$ reduces matrix metalloproteinase- $1,-3$ and -9 production by vascular smooth muscle cells. Cardiovasc Res 2001;50:556-565.

61 Henney AM, Wakeley PR, Davies MJ, et al: Localization of stromelysin gene expression in atherosclerotic plaques by in situ hybridization. Proc Natl Acad Sci USA 1991;88: 8154-8158.

62 Quinones S, Saus J, Otani Y, Harris ED Jr, Kurkinen M: Transcriptional regulation of human stromelysin. J Biol Chem 1989;264: 8339-8344.

63 Ugwu F, Lemmens G, Collen D, Lijnen HR: Matrix metalloproteinase deficiencies do not impair cell-associated fibrinolytic activity. Thromb Res 2001;102:61-69.

64 Johnson JL, Dwivedi A, Somerville M, George SJ, Newby AC: Matrix metalloproteinase (MMP)-3 activates MMP-9 mediated vascular smooth muscle cell migration and neointima formation in mice. Arterioscler Thromb Vasc Biol 2011;31:e35-e44.

65 Ye S, Humphries S, Henney A: Matrix metalloproteinases: implication in vascular matrix remodelling during atherogenesis. Clin Sci 1998;94:103-110.

66 Ye S, Watts GF, Mandalia S, Humphries SE, Henney AM: Preliminary report: genetic variation in the human stromelysin promoter is associated with progression of coronary atherosclerosis. Br Heart J 1995;73:209-215.

67 Rodriguez JA, Orbe J, Martinez de Lizarrondo S, et al: Metalloproteinases and atherothrombosis: MMP-10 mediates vascular remodeling promoted by inflammatory stimuli. Front Biosci 2008;13:2916-2921.

68 Montero I, Orbe J, Varo N, et al: C-reactive protein induces matrix metalloproteinase-1 and -10 in human endothelial cells: implications for clinical and subclinical atherosclerosis. J Am Coll Cardiol 2006;47:1369-1378.
69 Schonbeck U, Mach F, Sukhova GK, et al: Expression of stromelysin-3 in atherosclerotic lesions: regulation via CD40-CD40 ligand signaling in vitro and in vivo. J Exp Med 1999; 189:843-853.

70 Halpert I, Sires UI, Roby JD, et al: Matrilysin is expressed by lipid-laden macrophages at sites of potential rupture in atherosclerotic lesions and localizes to areas of versican deposition, a proteoglycan substrate for the enzyme. Proc Natl Acad Sci USA 1996;93:9748-9753.

71 Abbas A, Aukrust P, Russell D, et al: Matrix metalloproteinase 7 is associated with symptomatic lesions and adverse events in patients with carotid atherosclerosis. PLoS One 2014; 9:e84935.

72 Burke B, Giannoudis A, Corke KP, et al: Hypoxia-induced gene expression in human macrophages: implications for ischemic tissues and hypoxia-regulated gene therapy. Am J Pathol 2003;163:1233-1243.

73 Williams H, Johnson JL, Jackson CL, White SJ, George SJ: MMP-7 mediates cleavage of $\mathrm{N}$-cadherin and promotes smooth muscle cell apoptosis. Cardiovasc Res 2010;87:137-146.

74 Rajavashisth TB, Xu XP, Jovinge S, et al: Membrane type 1 matrix metalloproteinase expression in human atherosclerotic plaques: evidence for activation by proinflammatory mediators. Circulation 1999;99:3103-3109.

75 Rajavashisth TB, Liao JK, Galis ZS, et al: Inflammatory cytokines and oxidized low density lipoproteins increase endothelial cell expression of membrane type 1-matrix metalloproteinase. J Biol Chem 1999;274:1192411929.

76 Matias-Roman S, Galvez BG, Genis L, et al: Membrane type 1-matrix metalloproteinase is involved in migration of human monocytes and is regulated through their interaction with fibronectin or endothelium. Blood 2005; 105:3956-3964.

77 Aguilera CM, George SJ, Johnson JL, Newby AC: Relationship between type IV collagen degradation, metalloproteinase activity and smooth muscle cell migration and proliferation in cultured human saphenous vein. Cardiovasc Res 2003;58:679-688.

78 Ray BK, Shakya A, Turk JR, Apte SS, Ray A: Induction of the MMP-14 gene in macrophages of the atherosclerotic plaque: role of SAF-1 in the induction process. Circ Res 2004;95:1082-1090.

79 Johnson JL, Jenkins NP, Huang WC, et al: Relationship of MMP-14 and TIMP-3 expression with macrophage activation and human atherosclerotic plaque vulnerability. Mediators Inflamm 2014;2014:276457.

80 Valentin F, Bueb JL, Kieffer P, Tschirhart E, Atkinson J: Oxidative stress activates MMP-2 in cultured human coronary smooth muscle cells. Fundam Clin Pharmacol 2005;19:661-667.

81 Holmbeck K, Bianco P, Caterina J, et al: MT1MMP-deficient mice develop dwarfism, osteopenia, arthritis, and connective tissue disease due to inadequate collagen turnover. Cell 1999;99:81-92. 
82 Schneider F, Sukhova GK, Aikawa M, et al: Matrix-metalloproteinase-14 deficiency in bone-marrow-derived cells promotes collagen accumulation in mouse atherosclerotic plaques. Circulation 2008;117:931-939.

83 Uzui H, Harpf A, Liu M, et al: Increased expression of membrane type 3-matrix metalloproteinase in human atherosclerotic plaque: role of activated macrophages and inflammatory cytokines. Circulation 2002;106:30243030.

84 Jeng AY, Chou M, Sawyer WK, et al: Enhanced expression of matrix metalloproteinase- $3,-12$, and -13 mRNAs in the aortas of apolipoprotein E-deficient mice with advanced atherosclerosis. Ann NY Acad Sci 1999;878:555-558.

85 Chistiakov DA, Sobenin IA, Orekhov AN: Vascular extracellular matrix in atherosclerosis. Cardiol Rev 2013;21:270-288.

86 Wang X, Liang J, Koike T, et al: Overexpression of human matrix metalloproteinase-12 enhances the development of inflammatory arthritis in transgenic rabbits. Am J Pathol 2004; $165: 1375-1383$

87 Fan J, Wang X, Wu L, et al: Macrophage-specific overexpression of human matrix metalloproteinase-12 in transgenic rabbits. Transgenic Res 2004;13:261-269.

88 Shipley JM, Wesselschmidt RL, Kobayashi DK, Ley TJ, Shapiro SD: Metalloelastase is required for macrophage-mediated proteolysis and matrix invasion in mice. Proc Natl Acad Sci USA 1996;93:3942-3946.

89 Scholtes VP, Johnson JL, Jenkins N, et al: Carotid atherosclerotic plaque matrix metalloproteinase-12-positive macrophage subpopulation predicts adverse outcome after endarterectomy. J Am Heart Assoc 2012;1:e001040.

90 Traylor M, Makela KM, Kilarski LL, et al: A novel MMP12 locus is associated with large artery atherosclerotic stroke using a genomewide age-at-onset informed approach. PLoS Genet 2014;10:e1004469.

91 Yu Y, Koike T, Kitajima S, et al: Temporal and quantitative analysis of expression of metalloproteinases (MMPs) and their endogenous inhibitors in atherosclerotic lesions. Histol Histopathol 2008;23:1503-1516.

92 Brew K, Dinakarpandian D, Nagase H: Tissue inhibitors of metalloproteinases: evolution, structure and function. Biochim Biophys Acta 2000;1477:267-283.

93 Baker AH, Edwards DR, Murphy G: Metalloproteinase inhibitors: biological actions and therapeutic opportunities. J Cell Sci 2002; 115(Pt 19):3719-3727.

94 Fabunmi RP, Baker AH, Murray EJ, Booth RF, Newby AC: Divergent regulation by growth factors and cytokines of 95 and $72 \mathrm{kDa}$ gelatinases and tissue inhibitors or metalloproteinases-1, -2 , and -3 in rabbit aortic smooth muscle cells. Biochem J 1996;315(Pt 1):335-342.
95 Fabunmi RP, Sukhova GK, Sugiyama S, Libby P: Expression of tissue inhibitor of metalloproteinases- 3 in human atheroma and regulation in lesion-associated cells: a potential protective mechanism in plaque stability. Circ Res 1998;83:270-278.

96 Clark IM, Swingler TE, Sampieri CL, Edwards DR: The regulation of matrix metalloproteinases and their inhibitors. Int J Biochem Cell Biol 2008;40:1362-1378.

97 Silence J, Collen D, Lijnen HR: Reduced atherosclerotic plaque but enhanced aneurysm formation in mice with inactivation of the tissue inhibitor of metalloproteinase-1 (TIMP-1) gene. Circ Res 2002;90:897-903.

98 Moreau M, Brocheriou I, Petit L, Ninio E, Chapman MJ, Rouis M: Interleukin-8 mediates downregulation of tissue inhibitor of metalloproteinase- 1 expression in cholesterol-loaded human macrophages: relevance to stability of atherosclerotic plaque. Circulation 1999;99:420-426.

99 Zaltsman AB, George SJ, Newby AC: Increased secretion of tissue inhibitors of metalloproteinases 1 and 2 from the aortas of cholesterol fed rabbits partially counterbalances increased metalloproteinase activity. Arterioscler Thromb Vasc Biol 1999;19: 1700-1707.

100 Leco KJ, Khokha R, Pavloff N, Hawkes SP, Edwards DR: Tissue inhibitor of metalloproteinases-3 (TIMP-3) is an extracellular matrix-associated protein with a distinctive pattern of expression in mouse cells and tissues. J Biol Chem 1994;269:9352-9360.

101 Koskivirta I, Rahkonen O, Mayranpaa M, et al: Tissue inhibitor of metalloproteinases 4 (TIMP4) is involved in inflammatory processes of human cardiovascular pathology. Histochem Cell Biol 2006;126:335-342.

102 Spinale FG: Matrix metalloproteinases: regulation and dysregulation in the failing heart. Circ Res 2002;90:520-530.

103 Dollery CM, McEwan JR, Wang M, Sang QA, Liu YE, Shi YE: TIMP-4 is regulated by vascular injury in rats. Circ Res 1999;84: 498-504.

104 Vickers KC, Rye KA, Tabet F: MicroRNAs in the onset and development of cardiovascular disease. Clin Sci 2014;126:183-194.

105 Chavali S, Bruhn S, Tiemann K, et al: MicroRNAs act complementarily to regulate disease-related mRNA modules in human diseases. RNA 2013;19:1552-1562.

106 Son DJ, Kumar S, Takabe W, et al: The atypical mechanosensitive microRNA-712 derived from pre-ribosomal RNA induces endothelial inflammation and atherosclerosis. Nat Commun 2013;4:3000.

107 Kishore A, Borucka J, Petrkova J, Petrek M: Novel insights into miRNA in lung and heart inflammatory diseases. Mediators Inflamm 2014;2014:259131.
108 Fan X, Wang E, Wang X, Cong X, Chen X MicroRNA-21 is a unique signature associated with coronary plaque instability in humans by regulating matrix metalloproteinase-9 via reversion-inducing cysteine-rich protein with Kazal motifs. Exp Mol Pathol 2014;96:242-249.

109 Chen KC, Wang YS, Hu CY, et al: OxLDL up-regulates microRNA-29b, leading to epigenetic modifications of MMP-2/MMP-9 genes: a novel mechanism for cardiovascular diseases. FASEB J 2011;25:1718-1728.

110 Yuan M, Zhan Q, Duan X, et al: A functional polymorphism at miR-491-5p binding site in the 3'-UTR of MMP-9 gene confers increased risk for atherosclerotic cerebral infarction in a Chinese population. Atherosclerosis 2013;226:447-452.

111 Cipollone F, Felicioni L, Sarzani R, et al: A unique microRNA signature associated with plaque instability in humans. Stroke 2011; 42:2556-2563.

112 Di Gregoli K, Jenkins N, Salter R, White S, Newby AC, Johnson JL: MicroRNA-24 regulates macrophage behavior and retards atherosclerosis. Arterioscler Thromb Vasc Biol 2014;34:1990-2000.

113 Eldrup N, Gronholdt ML, Sillesen H, Nordestgaard BG: Elevated matrix metalloproteinase- 9 associated with stroke or cardiovascular death in patients with carotid stenosis. Circulation 2006;114:1847-1854.

114 Tan C, Liu Y, Li W, et al: Associations of matrix metalloproteinase- 9 and monocyte chemoattractant protein- 1 concentrations with carotid atherosclerosis, based on measurements of plaque and intima-media thickness. Atherosclerosis 2014;232:199-203.

115 Silvello D, Narvaes LB, Albuquerque LC, et al: Serum levels and polymorphisms of matrix metalloproteinases (MMPs) in carotid artery atherosclerosis: higher MMP-9 levels are associated with plaque vulnerability. Biomarkers 2014;19:49-55.

116 Alvarez B, Ruiz C, Chacon P, Alvarez-Sabin J, Matas M: Serum values of metalloproteinase- 2 and metalloproteinase- 9 as related to unstable plaque and inflammatory cells in patients with greater than $70 \%$ carotid artery stenosis. J Vasc Surg 2004;40:469-475.

117 Sapienza P, di Marzo L, Borrelli V, et al: Metalloproteinases and their inhibitors are markers of plaque instability. Surgery 2005; 137:355-363.

118 Sapienza P, Borrelli V, di Marzo L, Cavallaro A: MMP and TIMP alterations in asymptomatic and symptomatic severe recurrent carotid artery stenosis. Eur J Vasc Endovasc Surgery 2009;37:525-530.

119 Gaubatz JW, Ballantyne CM, Wasserman BA, et al: Association of circulating matrix metalloproteinases with carotid artery characteristics: the Atherosclerosis Risk in Communities Carotid MRI Study. Arterioscler Thromb Vasc Biol 2010;30:1034-1042. 
120 Peeters W, Moll FL, Vink A, et al: Collagenase matrix metalloproteinase- 8 expressed in atherosclerotic carotid plaques is associated with systemic cardiovascular outcome. Eur Heart J 2011;32:2314-2325.

121 Turu MM, Krupinski J, Catena E, et al: Intraplaque MMP-8 levels are increased in asymptomatic patients with carotid plaque progression on ultrasound. Atherosclerosis 2006; 187:161-169.

122 Orbe J, Montero I, Rodriguez JA, Beloqui O, Roncal C, Paramo JA: Independent association of matrix metalloproteinase-10, cardiovascular risk factors and subclinical atherosclerosis. J Thromb Haemost 2007;5:91-97.

123 Paramo JA, Beloqui O, Rodriguez JA, Diez J, Orbe J: Association between matrix metalloproteinase- 10 concentration and smoking in individuals without cardiovascular disease. Rev Esp Cardiol 2008;61:1267-1273.

124 Kawabe J, Hasebe N: Role of the vasa vasorum and vascular resident stem cells in atherosclerosis. Biomed Res Int 2014;2014:701571.

125 Michel JB, Thaunat O, Houard X, Meilhac O, Caligiuri G, Nicoletti A: Topological determinants and consequences of adventitial responses to arterial wall injury. Arterioscler Thromb Vasc Biol 2007;27:1259-1268.

126 Jeziorska M, Woolley DE: Local neovascularization and cellular composition within vulnerable regions of atherosclerotic plaques of human carotid arteries. J Pathol 1999;188: 189-196.

127 Eriksson EE: Intravital microscopy on atherosclerosis in apolipoprotein e-deficient mice establishes microvessels as major entry pathways for leukocytes to advanced lesions. Circulation 2011;124:2129-2138.

128 McCarthy MJ, Loftus IM, Thompson MM, et al: Angiogenesis and the atherosclerotic carotid plaque: an association between symptomatology and plaque morphology. J Vasc Surg 1999;30:261-268.

129 Hellings WE, Peeters W, Moll FL, et al: Composition of carotid atherosclerotic plaque is associated with cardiovascular outcome: a prognostic study. Circulation 2010; 121:1941-1950.

130 Ito TK, Ishii G, Saito S, et al: Degradation of soluble VEGF receptor-1 by MMP-7 allows VEGF access to endothelial cells. Blood 2009;113:2363-2369.

131 Mazor R, Alsaigh T, Shaked H, et al: Matrix metalloproteinase-1-mediated up-regulation of vascular endothelial growth factor-2 in endothelial cells. J Biol Chem 2013; 288:598-607.

132 Pepper MS: Role of the matrix metalloproteinase and plasminogen activator-plasmin systems in angiogenesis. Arterioscler Thromb Vasc Biol 2001;21:1104-1117.

133 Taraboletti G, D’Ascenzo S, Borsotti P, Giavazzi $R$, Pavan A, Dolo V: Shedding of the matrix metalloproteinases MMP-2, MMP-9, and MT1-MMP as membrane vesicle-associated components by endothelial cells. Am J Pathol 2002;160:673-680.
134 Jadhav U, Chigurupati S, Lakka SS, Mohanam S: Inhibition of matrix metalloproteinase- 9 reduces in vitro invasion and angiogenesis in human microvascular endothelial cells. Int J Oncol 2004;25:1407-1414.

135 Shapiro S, Khodalev O, Bitterman H, Auslender R, Lahat N: Different activation forms of MMP-2 oppositely affect the fate of endothelial cells. Am J Physiol Cell Physiol 2010; 298:C942-C951.

136 Galvez BG, Matias-Roman S, Albar JP, Sanchez-Madrid F, Arroyo AG: Membrane type 1-matrix metalloproteinase is activated during migration of human endothelial cells and modulates endothelial motility and matrix remodeling. J Biol Chem 2001;276: 37491-37500.

137 Stratman AN, Saunders WB, Sacharidou A, et al: Endothelial cell lumen and vascular guidance tunnel formation requires MT1MMP-dependent proteolysis in 3-dimensional collagen matrices. Blood 2009;114: 237-247.

138 Fang C, Wen G, Zhang L, et al: An important role of matrix metalloproteinase- 8 in angiogenesis in vitro and in vivo. Cardiovasc Res 2013;99:146-155.

139 Liu XQ, Mao Y, Wang B, et al: Specific matrix metalloproteinases play different roles in intraplaque angiogenesis and plaque instability in rabbits. PLoS One 2014;9: e107851.

140 Fingleton B: MMPs as therapeutic targets still a viable option? Semin Cell Dev Biol 2008;19:61-68.

141 Marx N, Sukhova G, Murphy C, Libby P, Plutzky J: Macrophages in human atheroma contain PPAR $\gamma$ : differentiation-dependent peroxisomal proliferator-activated receptor $\gamma$ (PPAR $\gamma)$ expression and reduction of MMP-9 activity through PPAR $\gamma$ activation in mononuclear phagocytes in vitro. Am J Pathol 1998;153:17-23.

142 Marx N, Schonbeck U, Lazar MA, Libby P, Plutzky J: Peroxisome proliferator-activated receptor gamma activators inhibit gene expression and migration in human vascular smooth muscle cells. Circ Res 1998;83:10971103.

143 Aikawa M, Rabkin E, Sugiyama S, et al: An HMG-CoA reductase inhibitor, cerivastatin, suppresses growth of macrophages expressing matrix metalloproteinases and tissue factor in vivo and in vitro. Circulation 2001; 103:276-283.

144 Luan Z, Chase AJ, Newby AC: Statins inhibit secretion of metalloproteinases-1, $-2,-3$, and -9 from vascular smooth muscle cells and macrophages. Arterioscler Thromb Vasc Biol 2003;23:769-775.

145 Francis GA, Annicotte JS, Auwerx J: PPAR agonists in the treatment of atherosclerosis. Curr Opin Pharmacol 2003;3:186-191.

146 Bellosta S, Bernini F, Ferri N, et al: Direct vascular effects of HMG-CoA reductase inhibitors. Atherosclerosis 1998;137(suppl): S101-S109.
147 Furman C, Copin C, Kandoussi M, et al: Rosuvastatin reduces MMP-7 secretion by human monocyte-derived macrophages: potential relevance to atherosclerotic plaque stability. Atherosclerosis 2004;174:93-98.

148 Peterson JT: The importance of estimating the therapeutic index in the development of matrix metalloproteinase inhibitors. Cardiovasc Res 2006;69:677-687.

149 Dorman G, Cseh S, Hajdu I, et al: Matrix metalloproteinase inhibitors: a critical appraisal of design principles and proposed therapeutic utility. Drugs 2010;70:949-964.

150 de Smet BJ, de Kleijn D, Hanemaaijer R, et al: Metalloproteinase inhibition reduces constrictive arterial remodeling after balloon angioplasty: a study in the atherosclerotic Yucatan micropig. Circulation 2000; 101:2962-2967.

151 Araujo CM, Rando GA, Mauro MF, et al: Batimastat-eluting stent implantation for the treatment of coronary artery disease: results of the Brazilian pilot study (in Portuguese). Arq Bras Cardiol 2005;84:256-260.

152 van Beusekom HM, Post MJ, Whelan DM, de Smet BJ, Duncker DJ, van der Giessen WJ: Metalloproteinase inhibition by batimastat does not reduce neointimal thickening in stented atherosclerotic porcine femoral arteries. Cardiovasc Rad Med 2003;4:186191.

153 Johnson JL, Fritsche-Danielson R, Behrendt $M$, et al: Effect of broad-spectrum matrix metalloproteinase inhibition on atherosclerotic plaque stability. Cardiovasc Res 2006; 71:586-595.

154 Emingil G, Atilla G, Sorsa T, Luoto $H$, Kirilmaz L, Baylas H: The effect of adjunctive low-dose doxycycline therapy on clinical parameters and gingival crevicular fluid matrix metalloproteinase-8 levels in chronic periodontitis. J Periodontol 2004;75:106115.

155 Brown DL, Desai KK, Vakili BA, Nouneh C, Lee HM, Golub LM: Clinical and biochemical results of the metalloproteinase inhibition with subantimicrobial doses of doxycycline to prevent acute coronary syndromes (MIDAS) pilot trial. Arterioscler Thromb Vasc Biol 2004;24:733-738.

156 Axisa B, Loftus IM, Naylor AR, et al: Prospective, randomized, double-blind trial investigating the effect of doxycycline on matrix metalloproteinase expression within atherosclerotic carotid plaques. Stroke 2002; 33:2858-2864.

157 Fields GB: New strategies for targeting matrix metalloproteinases. Matrix Biol 2015; 44-46:239-246.

158 Engel CK, Pirard B, Schimanski S, et al: Structural basis for the highly selective inhibition of MMP-13. Chem Biol 2005;12:181189.

159 Agrawal A, Romero-Perez D, Jacobsen JA, Villarreal FJ, Cohen SM: Zinc-binding groups modulate selective inhibition of MMPs. ChemMedChem 2008;3:812-820. 
160 Takahashi K, Ikura M, Habashita $\mathrm{H}$, et al: Novel matrix metalloproteinase inhibitors: generation of lead compounds by the in silico fragment-based approach. Bioorg Med Chem 2005; 13:4527-4543.

161 Grams F, Brandstetter H, D’Alo S, et al: Pyrimidine-2,4,6-Triones: a new effective and selective class of matrix metalloproteinase inhibitors. Biol Chem 2001;382:1277-1285.

162 Hajduk PJ, Shuker SB, Nettesheim DG, et al: NMR-based modification of matrix metalloproteinase inhibitors with improved bioavailability. J Med Chem 2002;45:56285639.

163 Li C, Cantor WJ, Nili N, et al: Arterial repair after stenting and the effects of GM6001, a matrix metalloproteinase inhibitor. J Am Coll Cardiol 2002;39:1852-1858.

164 Johnson AR, Pavlovsky AG, Ortwine DF, et al: Discovery and characterization of a novel inhibitor of matrix metalloprotease-13 that reduces cartilage damage in vivo without joint fibroplasia side effects. J Biol Chem 2007;282:27781-27791.

165 Devel L, Garcia S, Czarny B, et al: Insights from selective non-phosphinic inhibitors of MMP-12 tailored to fit with an S1' loop canonical conformation. J Biol Chem 2010; 285:35900-35909.

166 Cheng XC, Wang Q, Fang H, Tang W, Xu WF: Design, synthesis and evaluation of novel sulfonyl pyrrolidine derivatives as matrix metalloproteinase inhibitors. Bioorg Med Chem 2008;16:5398-5404.

167 Wang X, Choe Y, Craik CS, Ellman JA: Design and synthesis of novel inhibitors of gelatinase B. Bioorg Med Chem Lett 2002;12: 2201-2204.

168 Ikejiri M, Bernardo MM, Meroueh SO, et al: Design, synthesis, and evaluation of a mechanism-based inhibitor for gelatinase A. J Org Chem 2005;70:5709-5712.

169 Devel L, Rogakos V, David A, et al: Development of selective inhibitors and substrate of matrix metalloproteinase-12. J Biol Chem 2006;281:11152-11160.

170 Quillard T, Tesmenitsky Y, Croce K, et al: Selective inhibition of matrix metalloproteinase-13 increases collagen content of established mouse atherosclerosis. Arterioscler Thromb Vasc Biol 2011;31:2464-2472.

171 Graf von Roedern E, Grams F, Brandstetter $\mathrm{H}$, Moroder L: Design and synthesis of malonic acid-based inhibitors of human neutrophil collagenase (MMP8). J Med Chem 1998;41:339-345.
172 Johnson JL, Devel L, Czarny B, et al: A selective matrix metalloproteinase-12 inhibitor retards atherosclerotic plaque development in apolipoprotein E-knockout mice. Arterioscler Thromb Vasc Biol 2011;31:528-535.

173 Devy L, Dransfield DT: New strategies for the next generation of matrix-metalloproteinase inhibitors: selectively targeting membrane-anchored MMPs with therapeutic antibodies. Biochem Res Int 2011;2011: 191670.

174 Devy L, Huang L, Naa L, et al: Selective inhibition of matrix metalloproteinase-14 blocks tumor growth, invasion, and angiogenesis. Cancer Res 2009;69:1517-1526.

175 Sela-Passwell N, Kikkeri R, Dym O, et al: Antibodies targeting the catalytic zinc complex of activated matrix metalloproteinases show therapeutic potential. Nat Med 2012; 18:143-147.

176 Pruijt JF, Fibbe WE, Laterveer L, et al: Prevention of interleukin-8-induced mobilization of hematopoietic progenitor cells in rhesus monkeys by inhibitory antibodies against the metalloproteinase gelatinase $\mathrm{B}$ (MMP-9). Proc Natl Acad Sci USA 1999;96: 10863-10868.

177 Rouis M, Adamy C, Duverger N, et al: Adenovirus-mediated overexpression of tissue inhibitor of metalloproteinase-1 reduces atherosclerotic lesions in apolipoprotein Edeficient mice. Circulation 1999;100:533540.

178 Johnson JL, Baker AH, Oka K, et al: Suppression of atherosclerotic plaque progression and instability by tissue inhibitor of metalloproteinase-2: involvement of macrophage migration and apoptosis. Circulation 2006; 113:2435-2444.

179 Casagrande V, Menghini R, Menini S, et al: Overexpression of tissue inhibitor of metalloproteinase 3 in macrophages reduces atherosclerosis in low-density lipoprotein receptor knockout mice. Arterioscler Thromb Vasc Biol 2012;32:74-81.

180 Guo YH, Gao W, Li Q, Li PF, Yao PY, Chen $\mathrm{K}$ : Tissue inhibitor of metalloproteinases-4 suppresses vascular smooth muscle cell migration and induces cell apoptosis. Life Sci 2004;75:2483-2493.

181 Nagase H, Brew K: Engineering of tissue inhibitor of metalloproteinases mutants as potential therapeutics. Arthritis Res 2002; 4(suppl 3):S51-S61.

182 Moulton KS, Vakili K, Zurakowski D, et al: Inhibition of plaque neovascularization reduces macrophage accumulation and progression of advanced atherosclerosis. Proc Natl Acad Sci USA 2003;100:4736-4741.
183 Moulton KS, Heller E, Konerding MA, Flynn E, Palinski W, Folkman J: Angiogenesis inhibitors endostatin or TNP-470 reduce intimal neovascularization and plaque growth in apolipoprotein E-deficient mice. Circulation 1999;99:1726-1732.

184 Yang SW, Lim L, Ju S, Choi DH, Song H: Effects of matrix metalloproteinase 13 on vascular smooth muscle cells migration via AktERK dependent pathway. Tissue Cell 2015; 47:115-121.

185 Holnthoner W, Kerenyi M, Groger M, Kratochvill F, Petzelbauer P: Regulation of matrilysin expression in endothelium by fibroblast growth factor-2. Biochem Biophys Res Commun 2006;342:725-733.

186 Partridge CR, Hawker JR Jr, Forough R: Overexpression of a secretory form of FGF-1 promotes MMP-1-mediated endothelial cell migration. J Cell Biochem 2000;78:487-499.

187 Burbridge MF, Coge F, Galizzi JP, Boutin JA, West DC, Tucker GC: The role of the matrix metalloproteinases during in vitro vessel formation. Angiogenesis 2002;5:215-226.

188 Girardi F, Franceschi E, Brandes AA: Cardiovascular safety of VEGF-targeting therapies: current evidence and handling strategies. Oncologist 2010;15:683-694.

189 Leppanen P, Koota S, Kholova I, et al: Gene transfers of vascular endothelial growth factor-A, vascular endothelial growth factor- $\mathrm{B}$, vascular endothelial growth factor-C, and vascular endothelial growth factor-D have no effects on atherosclerosis in hypercholesterolemic low-density lipoprotein-receptor/ apolipoprotein B48-deficient mice. Circulation 2005; 112:1347-1352.

190 Winnik S, Lohmann C, Siciliani G, et al: Systemic VEGF inhibition accelerates experimental atherosclerosis and disrupts endothelial homeostasis - implications for cardiovascular safety. Int J Cardiol 2013;168: 2453-2461.

191 Motzer RJ, Porta C, Vogelzang NJ, et al Dovitinib versus sorafenib for third-line targeted treatment of patients with metastatic renal cell carcinoma: an open-label, randomised phase 3 trial. Lancet Oncol 2014;15: 286-296.

192 Hutson TE, Lesovoy V, Al-Shukri S, et al: Axitinib versus sorafenib as first-line therapy in patients with metastatic renal-cell carcinoma: a randomised open-label phase 3 trial. Lancet Oncol 2013;14:1287-1294.

193 Rashdan S, Hanna N: Nintedanib for the treatment of non-small-cell lung cancer. Expert Opin Pharmacother 2014;15:729-739. 